\title{
Safety of discharge for children with cancer and febrile neutropenia off antibiotics using absolute neutrophil count threshold values as a surrogate marker for adequate bone marrow recovery
}

\author{
Matthew E. Campbell, MD11, Debra L. Friedman, MD, MS ${ }^{1,2}$, Daniel E. Dulek, MD¹, Zhiguo \\ Zhao, MS ${ }^{2,3,4}$, Yi Huang, MS ${ }^{2,3,4}$, and Adam J. Esbenshade, MD, $\mathbf{M S C I}^{1,2}$ \\ ${ }^{1}$ Department of Pediatrics, Vanderbilt University School of Medicine and the Monroe Carell Jr. \\ Children's Hospital at Vanderbilt, Nashville TN, USA \\ ${ }^{2}$ Vanderbilt-Ingram Cancer Center, Nashville, TN, USA \\ ${ }^{3}$ Vanderbilt Department of Biostatistics, Nashville, TN, USA \\ ${ }^{4}$ Vanderbilt Center for Quantitative Science, Nashville, TN, USA
}

\begin{abstract}
Background-Febrile neutropenia $(\mathrm{F} \& \mathrm{~N})$ is common among pediatric oncology patients. However, there is a lack of clarity regarding parameters whereby such patients have demonstrated adequate bone marrow recovery for hospital discharge and empiric antibiotic discontinuation.

Procedure-A retrospective review was performed for 350 episodes of $\mathrm{F} \& \mathrm{~N}$ occurring at a single institution between 2007 and 2012 in pediatric oncology patients who were afebrile for 24 hours and had no bacterial source identified. Seven-day post-discharge outcomes were assessed and compared based on absolute neutrophil count (ANC) at discharge in order to identify an optimal threshold.
\end{abstract}

Results-Overall seven-day readmission rates were low (17/350, 4.6\%), with patients discharged

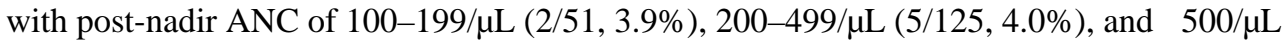
$(8 / 160,5.0 \%)$ all having similar rates. Patients with a discharge ANC $<100 / \mu \mathrm{L}(2 / 14,14.3 \%)$ had a higher readmission rate. A new bloodstream infection was identified upon readmission in one patient in each discharge ANC range except for ANC of 100-199/ $\mu \mathrm{L}$, in which none occurred. In a subset of 217 episodes where the ANC fell below 200/ $\mu \mathrm{L}$ during the admission and subsequently rose above 100/ $\mu \mathrm{L}, 94$ episodes resulted in 126 additional hospital days while subjects awaited further count recovery. One death occurred in a patient whose ANC at discharge was $290 / \mu \mathrm{L}$. This

Corresponding author: Dr. Adam J Esbenshade, MD, MSCI Vanderbilt Ingram Cancer Center, 2200 Pierce Ave., 397 PRB, Nashville, TN 37232, USA. Phone: (615) 936-1762 Fax: (615) 936-1767 adam.esbenshade @ vanderbilt.edu.

Author Contributions: All authors met criteria necessary for publication

1) Substantial contributions to conception and design, acquisition of data, or analysis and interpretation of data; 2) drafting the article or revising it critically for important intellectual content; 3) final approval of the version to be published; and 4) agreement to be accountable for all aspects of the work.

Conflicts of Interest: None to report. 
patient had received additional chemotherapy after count recovery and prior to discharge, and was readmitted with Clostridium tertium bacteremia.

Conclusion-These results suggest that a post-nadir ANC $>100 / \mu \mathrm{L}$ is a safe threshold value for empiric antibiotic discontinuation and discharge home.

\section{Keywords}

Febrile Neutropenia; Pediatric Oncology; Supportive Care; Health Services Research

\section{Introduction}

Febrile neutropenia $(\mathrm{F} \& \mathrm{~N})$ is a common occurrence in pediatric oncology patients due to myelosuppressive chemotherapy. There is consensus that these episodes require inpatient hospitalization and broad-spectrum parenteral antibiotics while evaluating for invasive bacterial disease.[1-3] However, less clarity exists regarding clinical parameters whereby such patients can be determined to have adequate count recovery for safe discharge home without further antibiotic treatment. Discharge criteria in many pediatric oncology programs and at this institution include afebrile status for $\geq 24$ hours with negative blood cultures for $\geq$ 48 hours, and evidence of bone marrow recovery at the time of discharge. Absolute neutrophil count (ANC) is most commonly used as a surrogate marker for adequate bone marrow recovery.[4] Pediatric-specific guidelines propose a post-nadir ANC greater than $100 / \mu \mathrm{L}$ as a reasonable threshold value for evidence of bone marrow recovery and safety of discharge home without antibiotics.[3] However, no studies examining specific threshold criteria for evidence of bone marrow recovery and patient outcomes based on commonly used threshold ANC values have been reported to support these guidelines. [5-8] Furthermore, the ANC threshold used remains variable across providers.[9] We sought to identify risk of recurrent infection and hospital readmission based on commonly used discharge ANC thresholds to better inform the appropriate ANC threshold for safe discontinuation of empiric antibiotics and discharge to home.

\section{Methods}

\section{Cohort Construction}

With Institutional Review Board approval, using an institutional database, an initial cohort was developed of 463 patients who were diagnosed with a childhood malignancy from 2007 to $2010,<23$ years of age at the time of diagnosis, and treated at the Monroe Carell Jr. Children's Hospital at Vanderbilt, a comprehensive cancer that treats all types of childhood cancer and performs stem cell transplants.

A review was then conducted using the electronic medical record to identify episodes of fever in those with ANC <500/ $\mu$ l between 2007 and 2012. Fever was defined as a temperature $\geq 38.0^{\circ} \mathrm{C}$ for $>$ one hour or $\geq 38.3^{\circ} \mathrm{C}$ for any duration.[10] Severe neutropenia was defined as ANC $<500 / \mu \mathrm{L}[10]$ and 549 episodes were identified in 228 patients. All patients were started on empiric intravenous (IV) antibiotics on the day of admission. Episodes were subsequently excluded if the patient did not have a central venous catheter (CVC) at presentation, if they had a preceding febrile event or received antibiotics within 7 
days of the identified episode, or if the patient had received a stem cell transplant within 30 days prior to the episode. Episodes were also excluded if the patient had an identified bacterial infection (blood stream or site infection) that required treatment with targeted antibiotics during the episode, or if the patient had not been afebrile for at least 24 hours when discharged. The resultant cohort of 350 discrete episodes was divided based on ANC values at discharge with subgroups of ANC $<100 / \mu \mathrm{L}(\mathrm{n}=14), \mathrm{ANC}=100-199 / \mu \mathrm{L}(\mathrm{n}=$ $51), \mathrm{ANC}=200-499 / \mu \mathrm{L}(\mathrm{n}=125)$, and ANC $\geq 500 / \mu \mathrm{L}(\mathrm{n}=160)$. A consort diagram can be found in Figure 1. It has previously been shown that monocyte production recovery often precedes neutrophil production recovery and that absolute monocyte count (AMC) or APC, defined as ANC + AMC, could be used as an early indicator of bone marrow recovery.[4,11] Thus a sub-analysis was conducted where the cohort was divided into absolute phagocyte count (APC) categories at discharge APC $>500 / \mu \mathrm{L}(\mathrm{n}=277)$ and APC $<500 / \mu \mathrm{L}(\mathrm{n}=73)$.

Demographic and exposure data were collected for all F\&N episodes in the cohort. This included patient age, gender, oncologic diagnosis, number of days since last intravenous IV chemotherapy, type of CVC, number of days that the CVC had been in place, and the clinical location of presentation for $\mathrm{F} \& \mathrm{~N}$. For each episode it was determined if granulocyte colony stimulating factor (G-CSF) was given after the most recent cycle of chemotherapy prior to the $\mathrm{F} \& \mathrm{~N}$ episode and if so the type and date of this administration was captured. Number of hospital days admitted for F\&N and number of days since last fever at time of discharge were collected. For all episodes, it was identified if empiric antibiotics were discontinued prior to discharge. All patients discharged after F\&N are instructed to followup after discharge from the hospital if they have recurrent fever or new concerning or worsening symptoms.

\section{Outcomes}

Primary outcomes assessed at seven days post discharge were presentation with new fever, receipt of empiric antibiotics, readmission for fever, identification of new blood stream infection (BSI), and mortality were compared between ANC at discharge subgroups. As there were some episodes when empiric antibiotics were stopped prior to discharge, a subanalysis of the same outcomes was assessed within seven days of empiric antibiotic cessation. Since a discharge ANC of $200 / \mu \mathrm{L}$ and ANC of $100 / \mu \mathrm{L}$ were the two most common thresholds used for discharge at Vanderbilt, a comparison was sought to see if using the lower threshold could prevent unnecessary hospital days. Thus a subset of episodes was identified in which the patient's ANC dropped below 200/ $\mu \mathrm{L}$, subsequently rose to greater than $100 / \mu \mathrm{L}$, the patient met other standard discharge criteria, and had no further documented indication for ongoing hospitalization apart from neutropenia. The number of additional hospital days spent while awaiting further ANC increase was then collected for this subset.

\section{Statistical Analysis}

Episode characteristics were summarized by subgroups defined by ANC at discharge $(<100 /$ $\mu \mathrm{L}, 100-199 / \mu \mathrm{L}, 200-499 / \mu \mathrm{L}$, and $2500 / \mu \mathrm{L}$ ) and overall. For continuous variables, median with lower and upper quartiles were reported. For categorical variables, frequencies and percentages were shown. For each of the predefined 7-day-post-discharge outcomes (New 
fever, Received empiric antibiotics, Readmitted for fever, and New BSI), the event frequency and rate were reported and comparted using Pearson's $\chi^{2}$ test among the ANC subgroups. The same outcomes were also compared between those with an APC $<500 / \mu \mathrm{L}$ and APC $\geq$ $500 / \mu \mathrm{L}$. All statistical inferences were assessed at a two-sided 5\% significant level. All statistical analyses were performed using $\mathrm{R}$ version 3.3 statistical software[12].

\section{Results \\ Cohort Characteristics}

Table 1 provides characteristics of the entire cohort and each ANC at discharge subgroup. Acute lymphoblastic leukemia was the underlying oncologic diagnosis more common in those with discharge ANC of $<100 / \mu \mathrm{L}(11 / 14,78.6 \%)$ and $100-199 / \mu \mathrm{L}(36 / 51,70.6 \%)$ compared to those with discharge ANC of $200-499 / \mu \mathrm{L}(64 / 125,51.2 \%)$ and $>=500 / \mu \mathrm{L}$ $(46 / 160,28.8 \%) \mathrm{p}=<0.01$. A port-a-cath was the predominant type of CVC in all subgroups but was more common in those discharged with ANC $<500 / \mu \mathrm{L}$ with $\mathrm{p}<0.01$. The percentage of patients who receiving G-CSF since their last cycle of chemotherapy increased by discharge subgroup with ANC of < 100/ $\mu \mathrm{L}(1 / 14,7.1 \%), 100-199 / \mu \mathrm{L}(6 / 51,11.8 \%), 200$ $299 / \mu \mathrm{L}(35 / 125,28.0 \%)$, and $\geq 500 / \mu \mathrm{L}(103 / 160,64.4 \%)$ and $\mathrm{p}<0.01$. There also was some variance in age, gender, and median number of days central line had been in place (all $\mathrm{p}<0.01)$. A limited number of episodes had patients receiving anti-infection prophylaxis including 307 on Pneumocystis jiroveci prophylaxis, 63 on fluconazole, 16 on acyclovir, 7 on voriconazole, 4 on nitrofurantoin, 1 on levofloxacin, 1 on ciprofloxacin, and 1 on cefixime.

\section{Seven-day outcomes}

Table 2 summarizes all seven day post-discharge outcomes all of which did not reach statistical significance, however some numeric differences will be described. Across the entire cohort $(n=350)$, new fever occurred within seven days of discharge in $26(7.4 \%)$ episodes. The occurrence of new fever was slightly higher for episodes with discharge ANC $\geq 500 / \mu \mathrm{L}(13 / 160,8.1 \%)$ compared to those with discharge ANC $200-499 / \mu \mathrm{L}(8 / 125$, $6.4 \%)$ and ANC $100-199 / \mu \mathrm{L}(2 / 51,3.9 \%, \mathrm{P}=0.57)$. Occurrence of new fever was also higher for episodes with discharge ANC $<100 / \mu \mathrm{L}(3 / 14,21.4 \%)$ compared with those had discharge ANC $>=100 / \mu \mathrm{L}(23 / 336,6.8 \%, \mathrm{P}=0.13)$. Receipt of new empiric antibiotics occurred within seven days of discharge in 20 (5.7\%) episodes (Table 2). The overall rate of restarting empiric antibiotics within each ANC cohort was similar between episodes with discharge ANC $100-199 / \mu \mathrm{L}(2 / 51,3.9 \%)$, ANC $200-499 / \mu \mathrm{L}(5 / 125,4.0 \%)$, and ANC $\geq$ $500 / \mu \mathrm{L}(11 / 160,6.9 \%, \mathrm{P}=0.50)$. Rate of restarting empiric antibiotics was higher for episodes with discharge ANC $<100 / \mu \mathrm{L}(2 / 14,14.3 \%, \mathrm{P}=0.41)$.

Readmission for fever occurred within seven days of discharge in 17 (4.6\%) episodes (Table 2). Similar readmission rates were seen for episodes with discharge ANC of 100-199/ $\mu \mathrm{L}$ (2/51, 3.9\%), 200-499/ $\mu \mathrm{L}(5 / 125,4.0 \%)$, and $\geq 500 / \mu \mathrm{L}(8 / 160,5.0 \%, \mathrm{P}=0.90)$ but trended higher for episodes with discharge ANC $<100 / \mu \mathrm{L}(2 / 14,14.3 \%, \mathrm{P}=0.30)$. New BSI was identified upon readmission in $3(0.9 \%)$ episodes. One new BSI occurred in episodes with discharge ANC $<100 / \mu \mathrm{L}$, ANC $200-499 / \mu \mathrm{L}$, and ANC $2500 / \mu \mathrm{L}$. 
Empiric antibiotics were stopped prior to discharge in 41 (11.7\%) of the episodes. The main reason documented for early stoppage of antibiotics included need for additional inpatient chemotherapy (9), need for rehabilitation (1), need for IV pain control (4), need for stem cell collection (2), nutritional concerns (11) and no discernable reason from the chart (14). The ANC was already $2200 / \mu \mathrm{L}$ at time of antibiotic cessation in $38(92.7 \%)$ of these episodes. None of these episodes resulted in a new fever or need to restart empiric antibiotics while still admitted to the hospital off antibiotics. Within seven days of discharge, a new fever occurred in $5(12.2 \%)$ episodes, and readmission occurred in $3(7.3 \%)$ of these episodes. In no episodes were IV antibiotics stepped down oral antibiotics.

\section{Characteristics of readmission episodes}

Table 3 provides characteristics for all seventeen episodes that resulted in hospital readmission within seven days of discharge. ANC at readmission was $<500 / \mu \mathrm{L}$ in ten $(58.8 \%)$ of the episodes, though two of these patients had received an additional cycle of chemotherapy prior to discharge from the initial F\&N hospitalization. One patient with a discharge ANC < 100/ $\mu \mathrm{L}$ was diagnosed with Streptococcus pneumoniae bacteremia upon readmission but stabilized on antibiotic therapy. There was one death that occurred within 72 hours of readmission from overwhelming sepsis related to Clostridium tertium bacteremia. This patient on initial F\&N admission had empiric antibiotics discontinued three days prior to discharge and then received further chemotherapy prior to discharge from the initial F\&N hospitalization. There was also one patient with a discharge ANC $>500 / \mathrm{uL}$ who was diagnosed with Candida albicans fungemia upon readmission but had no adverse outcome. Clostridium difficile colitis was diagnosed in $3(17.6 \%)$ of the readmitted patients. Two episodes were excluded from this study due to the presence of fever within 24 hours of discharge. One of these episodes resulted in readmission on day four post-discharge and the patient was diagnosed with Clostridium difficile colitis upon readmission.

\section{Additional hospital days}

In the subset of 217 episodes where the patient had a post-nadir ANC $\geq 100 / \mu \mathrm{L}$ and no further indication for ongoing hospitalization apart from neutropenia, 94 (43.3\%) patients remained hospitalized awaiting further ANC increase, resulting in 126 additional days of hospitalization (Table 4). Ten (10.6\%) of these patients had an ANC of $100-199 / \mu \mathrm{L}$ at discharge. Four (4.3\%) patients were readmitted for fever within seven days of discharge, with ANCs at discharge of $150 / \mu \mathrm{L}, 300 / \mu \mathrm{L}, 350 / \mu \mathrm{L}$, and $4860 / \mu \mathrm{L}$ respectively. Patients remained on empiric antibiotics for 107 of the additional hospital days. Antibiotics were stopped prior to discharge in 11 of the 94 episodes (11.7\%), which led to 19 of the additional hospital days occurring without empiric antibiotics.

Within this subset of episodes, the patients had received G-CSF since their last cycle of chemotherapy in 100 (46.1\%) episodes. Additional hospital days occurred in 40 (40\%) of these episodes, resulting in a total of 50 additional days awaiting count recovery. G-CSF was not given in 117 (53.9\%) of the episodes. Additional hospital days occurred in 54 (46\%) of these episodes, resulting in a total of 76 additional days awaiting count recovery. 


\section{APC at discharge}

Rate of readmission for fever was higher between those with a discharge APC $<500 / \mu \mathrm{L}$ $(7 / 73,9.6 \%)$ versus APC $\geq 500 / \mu \mathrm{L}(10 / 277,3.6 \%)$, however this did not reach statistical significance (Supplemental Table S1). Readmission occurred in two (7.1\%) episodes where the patient had a discharge APC $<500 / \mu \mathrm{L}$ and ANC $100-199 / \mu \mathrm{L}(\mathrm{n}=28)$. A new BSI was not isolated upon readmission in either episode. No readmissions or new BSI occurred in episodes where the patient had a discharge APC $2500 / \mu \mathrm{L}$ and ANC $<200 / \mu \mathrm{L}(\mathrm{n}=23)$.

\section{Discussion}

Evidence-based, pediatric-specific guidelines are available for the management of F\&N.[3] These guidelines include the standard discharge criteria that the patient must be afebrile for at least 24 hours, blood cultures remain negative for 48 hours, and the patient must have evidence of bone marrow recovery at the time of discharge. ANC is used as a surrogate marker of bone marrow recovery.[4] Prior studies have shown that patients discharged with an ANC $<500 / \mu \mathrm{L}$ are not at increased risk of adverse infectious outcomes, even in cases of prolonged neutropenia lasting greater than seven days, if they otherwise met standard discharge criteria and had hematologic evidence of bone marrow recovery.[5,6,8,13-15]

Previously published guidelines suggest a post-nadir ANC $>100 / \mu \mathrm{L}$ as a reasonable threshold value for evidence of bone marrow recovery and safety of discharge, but no studies cited in this recommendation specifically compared patient outcomes for threshold ANC values below 500/ $\mu \mathrm{L} .{ }^{3} \mathrm{~A}$ more recent study showed that patients with a discharge ANC of < $100 / \mu \mathrm{L}$ had a three-fold increase in readmission for fever compared to patients with a discharge ANC $2100 / \mu \mathrm{L}$.[16] However, this study also did not stratify outcomes for patients with discharge ANC values between $100 / \mu \mathrm{L}$ and $500 / \mu \mathrm{L}$. The present study is the first to look specifically at outcomes within subgroups based on commonly used discharge ANC thresholds $\leq 500 / \mu \mathrm{L}$. Furthermore, this study only included patients with a CVC, as the presence of a CVC is associated with increased risk of severe infection.[17,18]

Seven-day post-discharge readmission rates and recurrence of fever were similar between ANC at discharge subgroups of $100-199 / \mu \mathrm{L}, 200-499 / \mu \mathrm{L}$, and $2500 / \mu \mathrm{L}$ and there were few detected readmission bloodstream infections in any of the groups. One patient in the cohort died of overwhelming sepsis from Clostridium tertium bacteremia upon readmission, but this patient had a discharge ANC of $290 / \mu \mathrm{L}$ and had received another cycle of chemotherapy just prior to discharge. The readmission rate and new BSI occurrence in the episodes with discharge ANC $<100 / \mu \mathrm{L}$ were numerically higher however the sample size of this group is too low to draw conclusions.

Empiric antibiotics were stopped prior to discharge in a small percentage (11.7\%) of episodes. A new fever did not occur prior to discharge in any of these episodes. Three of these episodes resulted in readmission, two of which occurred within seven days of discharge and all of which had an ANC > 200/ $\mu \mathrm{L}$ on the day initial empiric antibiotics were stopped. Therefore, timing of antibiotic cessation had little impact on seven day outcome comparisons between subgroups. 
Overall, there is not enough data to make a conclusion regarding the safety of discharge for an ANC $<100 / \mu \mathrm{L}$. However, this data suggests there are equivalent outcomes for patients discharged at an ANC of $100-199 / \mathrm{uL}$ compared to those discharged at a higher threshold to support safe discharge home without continued antibiotic therapy in those with and ANC > 100/uL, supporting published guidelines.

Given that monocyte count recovery may precede neutrophil count recovery, some providers look at a rise in AMC or APC as an early indicator of imminent marrow recovery when considering discharge of patients admitted for F\&N.[4,11] In the present study, all primary outcomes, including readmission rate, were higher for episodes with APC $<500 / \mu \mathrm{L}$ compared to those with APC $\geq 500 / \mu \mathrm{L}$. Of note, no readmission or new BSI occurred for episodes with APC $2500 / \mu \mathrm{L}$ and ANC of $<200 / \mu \mathrm{L}$, but only seven of these episodes had an ANC $<100 / \mu \mathrm{L}$. These results suggest that an APC $>500 / \mu \mathrm{L}$ at discharge, even in the setting of an ANC $<100 / \mu \mathrm{L}$ could be a reasonable strategy. This would need to be evaluated in a larger cohort before any conclusions can be made.

Use of ANC $>100 / \mu \mathrm{L}$ as threshold for discharge home off empiric antibiotics can result in additional benefit with respect to hospital costs and decreased risk for nosocomial infection. In this cohort, a significant percentage (43.3\%) of patients who were otherwise ready for discharge were kept an additional 126 hospital days for further count recovery despite a post-nadir ANC > 100/ $\mathrm{LL}$. Receipt of G-CSF did not have a substantial impact on accrual of additional hospital days. Furthermore, four (4.3\%) of these patients were readmitted despite being kept additional hospital days, a readmission rate similar to the overall cohort readmission rate (4.6\%). Two of three patients in the cohort diagnosed with Clostridium difficile colitis upon readmission were kept additional hospital days with continued antibiotic treatment. Although this was not the focus of this study, it does underscore the risk of nosocomial infection associated with all $\mathrm{F} \& \mathrm{~N}$ admissions and prolonged treatment with empiric antibiotics.

There are several limitations to this study. Data was obtained through retrospective chart review and relied on accurate and detailed documentation in the medical record. This was particularly notable when determining indications for on-going hospitalization after standard discharge criteria had been met. The chart was checked for parameters such as poor oral intake status and need for IV medications, but this could have been incompletely documented. Episodes were excluded if a bacterial infection from any source of fever was identified and treated with targeted antimicrobial therapy. The sample size is modest and thus has limited power. Event rate was low for all primary outcomes. Particularly of note, very few patients were discharged with an ANC $<100 \mu \mathrm{L}$, so there was only $56 \%$ power for comparing new fever rate between ANC $100-199 / \mu \mathrm{L}$ and $<100 / \mu \mathrm{L}$ group to achieve a statistical significance at $5 \%$ type I error rate. This limits the conclusions that can be made about discharging patients with an ANC $<100 / \mu \mathrm{L}$.

Overall, the equivalent safety outcomes for patients discharged at an ANC of $100-199 / \mu \mathrm{L}$ compared to those discharged at a higher threshold supports the previous recommendation of a post-nadir ANC $>100 / \mu \mathrm{L}$ as a safe threshold for discharge to home off empiric antibiotics. Furthermore, adherence to this recommendation has the potential to reduce unnecessary 
health care utilization and nosocomial morbidity. Prospective implementation is needed to assess for changes in outcomes and health care utilization to establish the safety and efficacy of using this threshold and further solidify the recommendation.

\section{Supplementary Material}

Refer to Web version on PubMed Central for supplementary material.

\section{Acknowledgments}

Funding sources: NCRR/NIH; Grant number: CA090625 and KL2TR000446; NCI/NIH 2P30CA068485-19

\section{Abbreviations key}

F\&N $\quad$ Febrile neutropenia

ANC Absolute neutrophil count

IV Intravenous

CVC Central venous catheter

AMC Absolute monocyte count

APC Absolute phagocyte count

G-CSF Granulocyte colony stimulating factor

BSI Blood stream infection

\section{References}

1. Furno P, Bucaneve G, Del Favero A. Monotherapy or aminoglycoside-containing combinations for empirical antibiotic treatment of febrile neutropenic patients: a meta-analysis. The Lancet Infectious diseases 2002:2(4):231-242. [PubMed: 11937423]

2. Manji A, Lehrnbecher T, Dupuis LL, et al. A meta-analysis of antipseudomonal penicillins and cephalosporins in pediatric patients with fever and neutropenia. The Pediatric infectious disease journal 2012:31(4):353-358. [PubMed: 22173145]

3. Lehrnbecher T, Phillips R, Alexander S, et al. Guideline for the management of fever and neutropenia in children with cancer and/or undergoing hematopoietic stem-cell transplantation. Journal of clinical oncology : official journal of the American Society of Clinical Oncology 2012:30(35):4427-4438. [PubMed: 22987086]

4. Griffin TC, Buchanan GR. Hematologic predictors of bone marrow recovery in neutropenic patients hospitalized for fever: implications for discontinuation of antibiotics and early discharge from the hospital. The Journal of pediatrics 1992:121(1):28-33. [PubMed: 1625089]

5. Aquino VM, Buchanan GR, Tkaczewski I, et al. Safety of early hospital discharge of selected febrile children and adolescents with cancer with prolonged neutropenia. Medical and pediatric oncology 1997:28(3):191-195. [PubMed: 9024515]

6. Bash RO, Katz JA, Cash JV, et al. Safety and cost effectiveness of early hospital discharge of lower risk children with cancer admitted for fever and neutropenia. Cancer 1994:74(1):189-196. [PubMed: 8004575]

7. Mullen CA, Buchanan GR. Early hospital discharge of children with cancer treated for fever and neutropenia: identification and management of the low-risk patient. Journal of clinical oncology : 
official journal of the American Society of Clinical Oncology 1990:8(12):1998-2004. [PubMed: 2230891]

8. Aquino VM, Tkaczewski I, Buchanan GR. Early discharge of low-risk febrile neutropenic children and adolescents with cancer. Clinical infectious diseases : an official publication of the Infectious Diseases Society of America 1997:25(1):74-78. [PubMed: 9243037]

9. Mueller EL, Walkovich KJ, Yanik GA, et al. Variation in Management of Fever and Neutropenia Among Pediatric Patients With Cancer: A Survey of Providers in Michigan. Pediatric hematology and oncology 2015:32(5):331-340. [PubMed: 26086779]

10. Freifeld AG, Bow EJ, Sepkowitz KA, et al. Clinical practice guideline for the use of antimicrobial agents in neutropenic patients with cancer: 2010 Update by the Infectious Diseases Society of America. Clinical infectious diseases : an official publication of the Infectious Diseases Society of America 2011:52(4):427-431. [PubMed: 21205990]

11. Bhatnagar S, Chandra J, Narayan S. Hematological changes and predictors of bone marrow recovery in patients with neutropenic episodes in acute lymphoblastic leukemia. Journal of tropical pediatrics 2002:48(4):200-203. [PubMed: 12200979]

12. Team RC. R: A language and environment for statistical computing. R Foundation for Statistical Computing version 3.3 Vienna, Austria 2017.

13. Cohen KJ, Leamer K, Odom L, et al. Cessation of antibiotics regardless of ANC is safe in children with febrile neutropenia. A preliminary prospective trial. Journal of pediatric hematology/ oncology 1995:17(4):325-330. [PubMed: 7583388]

14. Lehrnbecher T, Stanescu A, Kuhl J. Short courses of intravenous empirical antibiotic treatment in selected febrile neutropenic children with cancer. Infection 2002:30(1):17-21. [PubMed: 11876510]

15. Hodgson-Viden H, Grundy PE, Robinson JL. Early discontinuation of intravenous antimicrobial therapy in pediatric oncology patients with febrile neutropenia. BMC pediatrics 2005:5(1):10. [PubMed: 15904510]

16. Villanueva MA, August KJ. Early Discharge of Neutropenic Pediatric Oncology Patients Admitted With Fever. Pediatric blood \& cancer 2016:63(10):1829-1833. [PubMed: 27196265]

17. Rondinelli PI, Ribeiro Kde C, de Camargo B. A proposed score for predicting severe infection complications in children with chemotherapy-induced febrile neutropenia. Journal of pediatric hematology/oncology 2006:28(10):665-670. [PubMed: 17023827]

18. Allen RC, Holdsworth MT, Johnson CA, et al. Risk determinants for catheter-associated blood stream infections in children and young adults with cancer. Pediatric blood \& cancer 2008:51(1): 53-58. [PubMed: 18266227] 
Diagnosed with malignancy between 2007 and 2010, less than 23 years old at time of diagnosis, and treated at $\mathrm{VCH}$

(463 patients)

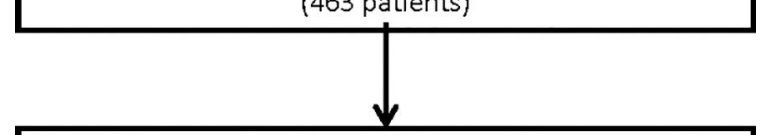

Fever and neutropenia between 2007 and 2012 Central venous line present No preceding febrile event or receipt of empiric antibiotics within 7 days of episode

No stem cell transplant within 30 days of episode (549 discrete episodes, 228 patients)

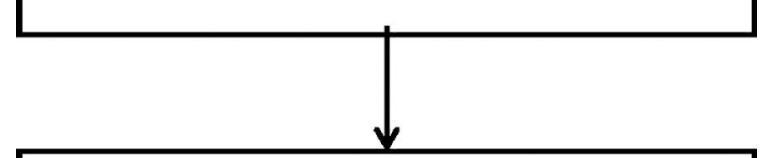

No positive blood culture identified during episode (447 episodes, 214 patients)

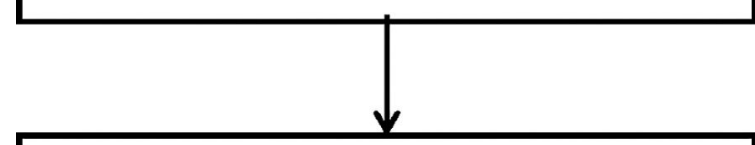

No other identified bacterial infection requiring treatment with targeted antibiotics during episode (352 episodes, 178 patients)

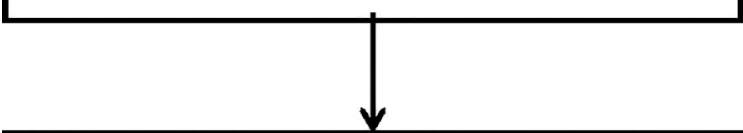

Afebrile for at least 24 hours at time of discharge (350 episodes, 178 patients)

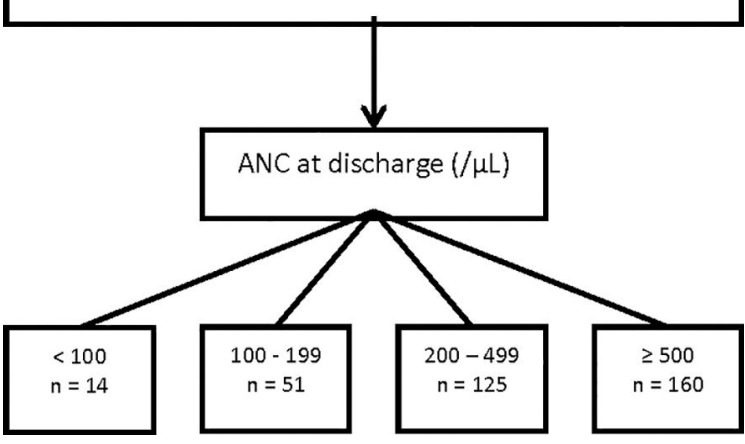

Figure 1:

Cohort construction. VCH indicates Vanderbilt Children's Hospital; ANC, absolute neutrophil count 
Table 1.

Patient Characteristics

\begin{tabular}{|c|c|c|c|c|c|c|}
\hline & \multirow{2}{*}{ Overall $(n=350)$} & \multirow[b]{2}{*}{$<100(n=14)$} & \multicolumn{3}{|c|}{$\begin{array}{l}\text { Absolute neutrophil count (ANC) at discharge (/ } \\
\mu \mathrm{L})\end{array}$} & \multirow[b]{2}{*}{ P Value* } \\
\hline & & & $\underset{51)}{100-199}(n=$ & $\begin{array}{c}200-499 \\
125)\end{array}(n=$ & $\triangle 00(n=160)$ & \\
\hline $\begin{array}{l}\text { Median age in years (with } 25 \\
-75 \% \text { ) }\end{array}$ & $7(3-11.25)$ & $5(3-9)$ & $6(4-11)$ & $5(3-10)$ & $8(4-13.75)$ & $<0.01$ \\
\hline \multicolumn{7}{|l|}{ Gender } \\
\hline Male & $208(59.4 \%)$ & $10(71.4 \%)$ & $30(58.8 \%)$ & $75(60.0 \%)$ & $93(58.1 \%)$ & $<0.01$ \\
\hline Female & $142(40.6 \%)$ & $4(28.6 \%)$ & $21(41.2 \%)$ & $50(40.0 \%)$ & $67(41.9 \%)$ & \\
\hline Oncologic Diagnosis & & & & & & $<0.01$ \\
\hline ALL & $157(44.9 \%)$ & $11(78.6 \%)$ & $36(70.6 \%)$ & $64(51.2 \%)$ & $46(28.8 \%)$ & \\
\hline AML & $21(6.0 \%)$ & $0(0 \%)$ & $1(2.0 \%)$ & $12(9.6 \%)$ & $8(5.0 \%)$ & \\
\hline NHL & $30(8.5 \%)$ & $1(7.1 \%)$ & $1(2.0 \%)$ & $11(8.8 \%)$ & $17(10.6 \%)$ & \\
\hline Hodgkins Lymphoma & $12(3.4 \%)$ & $0(0 \%)$ & $0(0 \%)$ & $4(3.2 \%)$ & $8(5.0 \%)$ & \\
\hline CNS Tumor & $23(6.5 \%)$ & $0(0 \%)$ & $3(5.9 \%)$ & $5(4.0 \%)$ & $15(9.4 \%)$ & \\
\hline Non-CNS solid tumor & $99(28.3 \%)$ & $1(7.1 \%)$ & $8(15.7 \%)$ & $28(22.4 \%)$ & $62(38.8 \%)$ & \\
\hline $\begin{array}{l}\text { Lymphoproliferative } \\
\text { Disorder (LCH, HLH, PTLD) }\end{array}$ & $5(1.4 \%)$ & $0(0 \%)$ & $0(0 \%)$ & $1(0.8 \%)$ & $4(2.5 \%)$ & \\
\hline $\begin{array}{l}\text { Other (individual diagnoses } \\
\text { listed in each subgroup) }\end{array}$ & $3(0.9 \%)$ & 1 (7.1\%); CML & $\begin{array}{c}2(3.8 \%) ; \mathrm{NK} \\
\text { cell Leukemia, } \\
\text { CML }\end{array}$ & $0(0.0 \%)$ & $0(0.0 \%)$ & \\
\hline $\begin{array}{l}\text { Median \# of days since last } \\
\text { IV/IT chemotherapy (with } 25 \\
-75 \% \text { ) }\end{array}$ & $7(5-10)$ & $8(4-16)$ & $7(3-13)$ & $7(5-12)$ & $7(5-9)$ & \\
\hline Type of CVC & & & & & & $<0.01$ \\
\hline Port & $228(65.1 \%)$ & $12(85.7 \%)$ & $45(88.2 \%)$ & $90(72.0 \%)$ & $81(50.6 \%)$ & \\
\hline Hickman & $110(31.4 \%)$ & $2(14.3 \%)$ & $6(11.8 \%)$ & $31(24.8 \%)$ & $71(44.4 \%)$ & \\
\hline PICC & $12(3.4 \%)$ & $0(0 \%)$ & $0(0 \%)$ & $4(3.2 \%)$ & $8(5.0 \%)$ & \\
\hline $\begin{array}{l}\text { Median \# of CVC days (with } \\
25-75 \% \text { ) }\end{array}$ & $106(48-227)$ & $148(73.75-230)$ & $\begin{array}{l}167(93.5- \\
369)\end{array}$ & $\begin{array}{l}125.5(65.75- \\
307)\end{array}$ & $\begin{array}{c}70.5(25.25- \\
161)\end{array}$ & $<0.01$ \\
\hline $\begin{array}{l}\text { Received G-CSF since last } \\
\text { cycle of chemotherapy }\end{array}$ & $145(41.4 \%)$ & $1(7.1 \%)$ & $6(11.8 \%)$ & $35(28.0 \%)$ & $103(64.4 \%)$ & $<0.01$ \\
\hline \multicolumn{7}{|l|}{ Type of G-CSF received } \\
\hline Neupogen & $89(61.4 \%)$ & $1(100 \%)$ & $4(66.7 \%)$ & $24(68.6 \%)$ & $60(58.3)$ & 0.596 \\
\hline Neulasta & $56(38.6 \%)$ & $0(0 \%)$ & $2(33.3 \%)$ & $11(31.4 \%)$ & $43(41.7 \%)$ & \\
\hline $\begin{array}{l}\text { Median \# of days G-CSF } \\
\text { received prior to discharge } \\
\text { (with } 25-75 \% \text { ) }\end{array}$ & $9(8-11)$ & 9 & $9(8.25-10.5)$ & $9(7-11)$ & $9(8-11)$ & 0.96 \\
\hline \multicolumn{7}{|l|}{ Location } \\
\hline Clinic & $112(32.0 \%)$ & $5(35.7 \%)$ & $17(33.3 \%)$ & $30(24.0 \%)$ & $60(37.5 \%)$ & \\
\hline ER & $199(56.9 \%)$ & $9(64.3 \%)$ & $32(62.7 \%)$ & $81(64.8 \%)$ & $77(48.1 \%)$ & \\
\hline Inpatient & $39(10.9 \%)$ & $0(0 \%)$ & $2(3.9 \%)$ & $14(11.2 \%)$ & $23(14.4 \%)$ & \\
\hline $\begin{array}{l}\text { Median \# of hospital days } \\
\text { (with } 25-75 \% \text { ) }\end{array}$ & $4(3-7)$ & $4(2.75-8.5)$ & $4(3-6)$ & $4(3-6.5)$ & $4(3-7)$ & \\
\hline $\begin{array}{l}\text { Median \# of days since last } \\
\text { fever at discharge (with 25- } \\
75 \% \text { ) }\end{array}$ & $3(2-5)$ & $3(2-6.5)$ & $3(2-5)$ & $3(2-5)$ & $3(2-5)$ & \\
\hline
\end{tabular}

Pediatr Blood Cancer. Author manuscript; available in PMC 2019 July 15. 
Abbreviations: ALL $=$ Acute Lymphoblastic Leukemia, $\mathrm{AML}=$ Acute Myeloid Leukemia, $\mathrm{NHL}=$ Non-Hodgkin Lymphoma, CNS $=$ Central Nervous System, LHC = Langerhans Cell Histiocytosis, HLH = Hemophagocytic Lymphohistiocytosis, PTLD = Post-transplant

Lymphoproliferative Disorder, $\mathrm{CML}=$ Chronic Myeloid Leukemia, IV = intravenous, IT = intrathecal, $\mathrm{CVC}=$ Central Venous Catheter, PICC =

Peripherally Inserted Central Catheter, G-CSF = Granulocyte Colony Stimulating Factor

*: From Pearson's $\chi^{2}$ test (categorical characteristics) or Kruskal-Wallis test (continuous characteristics) comparing any differences among ANC groups $(<100 / \mu \mathrm{L}, 100-199 / \mu \mathrm{L}, 200-499 / \mu \mathrm{L}$, and $2500 / \mu \mathrm{L})$ 
Table 2.

Seven day post-discharge outcomes

\begin{tabular}{|c|c|c|c|c|c|c|c|c|}
\hline \multirow{3}{*}{ ANC at discharge } & \multicolumn{8}{|c|}{ Outcomes } \\
\hline & \multicolumn{2}{|c|}{ New fever ${ }^{\$ \#}$} & \multicolumn{2}{|c|}{ Received empiric antibiotics $\$ \#$} & \multicolumn{2}{|c|}{ Readmitted for fever $\$ \#$} & \multicolumn{2}{|c|}{ New BSI ${ }^{\$ \#}$} \\
\hline & Summary & P-Value ${ }^{\$ \#}$ & Summary & P-Value ${ }^{\$ \#}$ & Summary & P-Value ${ }^{\$ \#}$ & Summary & P-Value ${ }^{\$ \#}$ \\
\hline$<100 / \mu \mathrm{L}(14)$ & $3(21.4 \%)$ & & $2(14.3 \%)$ & & $2(14.3 \%)$ & & $1(7.1 \%)$ & \\
\hline$\geq 100 / \mu \mathrm{L}(336)$ & $23(6.8 \%)$ & 0.129 & $18(5.4 \%)$ & 0.411 & $15(4.5 \%)$ & 0.298 & $2(0.6 \%)$ & 0.261 \\
\hline $100-199 / \mu \mathrm{L}(51)$ & $2(3.9 \%)$ & 0.107 & $2(3.9 \%)$ & 0.423 & $2(3.9 \%)$ & 0.423 & $0(0 \%)$ & 0.485 \\
\hline $200-499 / \mu \mathrm{L}(125)$ & $8(6.4 \%)$ & 0.146 & $5(4.0 \%)$ & 0.306 & $5(4.0 \%)$ & 0.306 & $1(0.8 \%)$ & 0.480 \\
\hline$\geq 500 / \mu \mathrm{L}(160)$ & $13(8.1 \%)$ & 0.242 & $11(6.9 \%)$ & 0.630 & $8(5.0 \%)$ & 0.405 & $1(0.6 \%)$ & 0.375 \\
\hline Overall (350) & $26(7.4 \%)$ & & $20(5.7 \%)$ & & $17(4.6 \%)$ & & $3(0.9 \%)$ & \\
\hline
\end{tabular}

Abbreviations: $\mathrm{ANC}=$ Absolute Neutrophil Count, $\mathrm{BSI}=$ Blood stream infection

Fever defined as temperature $>38^{\circ} \mathrm{C}$

$\$$ P values are compared with $<100 / \mu \mathrm{L}$ group.

\# $\mathrm{P}$ values for comparing $100-199 / \mu \mathrm{L}, 200-499 / \mu \mathrm{L}$ and $\geq 500 / \mu \mathrm{L}$ groups are $0.567,0.500,0.902$ and 0.820 for New fever, Received empiric antibiotics, Readmitted for fever, and New BSI respectively. 
Table 3.

Key characteristics of all seven day post-discharge readmissions

\begin{tabular}{|c|c|c|c|c|c|c|c|}
\hline $\begin{array}{l}\text { ANC at } \\
\text { discharge } \\
\text { subgroup } \\
(/ \mu \mathrm{L})\end{array}$ & $\begin{array}{l}\text { ANC, } \\
\text { APC at } \\
\text { discharge } \\
(/ \mu \mathrm{L})\end{array}$ & $\begin{array}{l}\text { G-CSF } \\
\text { received since } \\
\text { last cycle of } \\
\text { chemotherapy } \\
\text { prior to initial } \\
\text { FN episode }\end{array}$ & $\begin{array}{l}\text { Days } \\
\text { since last } \\
\text { fever at } \\
\text { discharge }\end{array}$ & Days to readmission & $\begin{array}{l}\text { ANC, APC at } \\
\text { time of } \\
\text { readmission }\end{array}$ & $\begin{array}{l}\text { Signs or } \\
\text { symptoms } \\
\text { of sepsis at } \\
\text { readmission }\end{array}$ & Organisms isolated on readmission \\
\hline \multirow[t]{2}{*}{$<100$} & 0,0 & No & 2 & 3 & 0,10 & None & Streptococcus pneumoniae bacteremia \\
\hline & 10,80 & No & 5 & 3 & 0,640 & None & None \\
\hline \multirow[t]{2}{*}{$100-199$} & 140,150 & No & 6 & 2 & 20,130 & None & C. difficile colitis \\
\hline & 160,160 & No & 7 & 7 & 430,430 & Chills & None \\
\hline \multirow[t]{5}{*}{$200-499$} & 260,300 & No & 3 & 1 & 330,150 & None & Parvovirus B19 PCR positive \\
\hline & 290,390 & No & 10 & 1 & 70,110 & $\begin{array}{l}\text { Hypotension, } \\
\text { Altered } \\
\text { Mental } \\
\text { Status }\end{array}$ & Clostridium tertium bacteremia ${ }^{*}$ \\
\hline & 320,350 & No & 4 & 7 & 90,200 & None & None \\
\hline & 350,860 & Yes & 2 & 2 & $14,350,16,560$ & Hypotension & C. difficile colitis \\
\hline & 470,650 & No & 3 & 7 & 130,260 & None & None \\
\hline \multirow[t]{8}{*}{$\geq 500$} & 580,620 & No & 2 & 6 & 150,60 & None & None \\
\hline & 1090,1470 & No & 4 & 3 & 920,1170 & Chills & C. difficile colitis \\
\hline & 1550,2020 & Yes & 1 & 1 & 2390,3000 & Chills & None \\
\hline & 1640,2560 & No & 4 & 5 & 4980,5020 & None & None \\
\hline & 1640,4860 & Yes & 4 & 1 & 1550,2320 & Chills & None \\
\hline & 1690,2090 & No & 14 & 4 & 13110,14620 & None & None \\
\hline & 6610,6620 & Yes & 9 & 1 & 60,60 & None & Candida albicans fungemia \\
\hline & 6960,9620 & Yes & 2 & 6 & 3960,4090 & None & None \\
\hline
\end{tabular}

Abbreviations: $\mathrm{ANC}=$ Absolute Neutrophil Count, $\mathrm{APC}=$ Absolute Phagocyte Count, G-CSF $=$ Granulocyte Colony Stimulating Factor

Patient died of overwhelming sepsis related bacteremia upon readmission; patient also received intravenous chemotherapy on the day prior to discharge from initial F\&N hospitalization

Pediatr Blood Cancer. Author manuscript; available in PMC 2019 July 15. 
Table 4.

Additional Hospital Days

\begin{tabular}{|c|c|c|c|c|}
\hline \# of extra days ${ }^{*}$ & $\mathbf{0}$ & 1 & 2 & 3 or more \\
\hline \multicolumn{5}{|c|}{ ANC at discharge $(/ \mu \mathrm{L})$} \\
\hline $100-199(48)$ & $38(79.2 \%)$ & $10(20.8 \%)$ & $0(0 \%)$ & $0(0 \%)$ \\
\hline $200-499(86)$ & $48(55.8 \%)$ & $26(30.2 \%)$ & $8(9.3 \%)$ & $4(4.7 \%)$ \\
\hline$\geq 500(83)$ & $37(44.6 \%)$ & $34(41.0 \%)$ & $9(10.8 \%)$ & $3(3.6 \%)$ \\
\hline Overall (217) & $123(56.7 \%)$ & $70(32.3 \%)$ & $17(7.8 \%)$ & $7(3.2 \%)$ \\
\hline \multicolumn{5}{|c|}{ Received G-CSF, By ANC at discharge $(/ \mu \mathrm{L})$} \\
\hline 100-199 (6) & $6(100 \%)$ & $0(0 \%)$ & $0(0 \%)$ & $0(0 \%)$ \\
\hline $200-499(32)$ & $24(75 \%)$ & $8(25 \%)$ & $0(0 \%)$ & $0(0 \%)$ \\
\hline$\geq 500(62)$ & $30(48.4 \%)$ & $25(40.3 \%)$ & $5(8.1 \%)$ & $2(3.2 \%)$ \\
\hline Overall (100) & $60(60.0 \%)$ & $33(33.0 \%)$ & $5(5.0 \%)$ & $2(2.0 \%)$ \\
\hline \multicolumn{5}{|c|}{ Did not receive G-CSF, By ANC at discharge $(/ \mu \mathrm{L})$} \\
\hline $100-199(42)$ & $32(76.2 \%)$ & $10(23.8 \%)$ & $0(0 \%)$ & $0(0 \%)$ \\
\hline $200-499(54)$ & $24(44.4 \%)$ & $18(33.3 \%)$ & $8(14.8 \%)$ & $4(7.4 \%)$ \\
\hline$\geq 500(21)$ & $7(33.3 \%)$ & $9(42.9 \%)$ & $4(19.0 \%)$ & $1(4.8 \%)$ \\
\hline Overall (117) & $63(53.8 \%)$ & $37(31.6 \%)$ & $12(10.3 \%)$ & $5(4.3 \%)$ \\
\hline
\end{tabular}

Abbreviations: ANC $=$ Absolute Neutrophil Count, G-CSF $=$ Granulocyte Colony Stimulating Factor

* Patients remained on empiric antibiotics for 107 of the additional hospital days. Antibiotics were stopped prior to discharge in 11 of the 94 episodes (11.7\%), which led to 19 of the additional hospital days occurring without empiric antibiotics. 